\title{
QUIMILUMINESCÊNCIA DE PERÓXIDOS ORGÂNICOS: GERAÇÃO DE ESTADOS ELETRONICAMENTE EXCITADOS NA DECOMPOSIÇÃO DE 1,2-DIOXETANOS
}

\author{
Ana L. P. Nery e Wilhelm J. Baader* \\ Instituto de Química, Universidade de São Paulo, CP 26077, 05513-970 São Paulo - SP
}

Recebido em 19/5/00; aceito em 12/3/01

\begin{abstract}
CHEMILUMINESCENCE OF CYCLIC ORGANIC PEROXIDES: GENERATION OF ELECTRONICALLY EXCITED STATES IN 1,2-DIOXETANE DECOMPOSITION. In this review article, we give a general introduction on the mechanisms involved in organic chemiluminescence, where three basic models for excited state formation are presented. The chemiluminescence properties of 1,2-dioxetanes - four membered ring peroxides - are briefly outlined in the second part. In the main part, the mechanisms involved in the decomposition of 1,2-dioxetanes and analogous peroxides are discussed: (i) the unimolecular decomposition of 1,2-dioxetanes; (ii) the electron transfer catalyzed decomposition of peroxides by an intermolecular CIEEL (Chemically Initiated Electron Exchange Luminescence) mechanism; (iii) 1,2-dioxetane decomposition catalyzed by an intramolecular electron transfer mechanism (intramolecular CIEEL). Special emphasis is given to the latter subject, where recent examples with potential analytical applications are presented.
\end{abstract}

Keywords: 1,2-dioxetanes; peroxide decomposition; chemiluminescence; CIEEL (Chemically Initiated Electron Exchange Luminescence).

\section{PRINCÍPIOS DA QUIMILUMINESCÊNCIA}

A geração de luz visível por um organismo vivo ou através de uma reação química é um evento tão peculiar a ponto de atrair o interesse de biólogos, bioquímicos e químicos ${ }^{1}$. Da Sibéria ao Novo México, da Europa à China, os primeiros escritos da civilização humana contêm referências e mitologias sobre animais luminosos, tais como vaga-lumes ou pirilampos, e sobre fenômenos tais como corpos brilhantes e florestas incandescentes. Entretanto, foram os gregos os primeiros a relatar suas características peculiares. Aristóteles (384-322 a.C.) parece ser um dos primeiros escritores a relatar a "luz fria" Os pirilampos foram denominados pelos gregos lamparinas porque brilham no escuro como uma faísca de fogo ${ }^{1}$. Ao contrário de muitos processos naturais, é difícil atribuir a uma única pessoa a descoberta da quimiluminescência, entretanto, é possível identificar certas observações e experimentos responsáveis por esta primeira definição. No início do século XX, com o avanço científico e tecnológico levando a descobertas importantes, foi possível associar quimiluminescência a reações químicas que produzem estados eletronicamente excitados, em quantidade necessária e com rapidez suficiente, permitindo a observação da emissão de luz a olho nu.

Nas últimas décadas, talvez estimulado pela mera peculiaridade e singularidade de tais eventos, o interesse em reações bio e quimiluminescentes tem crescido e se diversificado significativamente. Entretanto, até meados dos anos 70, artigos de revisão sobre quimiluminescência em solução podiam ser descritos como belos catálogos contendo uma série complexa de reações e alguns comentários mecanísticos, ilustrados somente com exemplos em fase gasosa.

Num processo quimiluminescente, o estado eletronicamente excitado é gerado através de uma reação química. A questão fundamental a respeito deste processo: "Por que algumas reações geram produtos eletronicamente excitados, quando poderiam gerar as mesmas espécies no estado fundamental?" continua até hoje, de certa forma, mal respondida, apesar de alguns requisitos básicos serem facilmente identificados. Para que possa-

e-mail: wjbaader@iq.usp.br mos entender o processo, tentaremos expor sucintamente as características fundamentais de três tipos de reações, a saber, reação química exotérmica, reação fotoquímica ("foto-energizada") e reação quimiluminescente ("quimio-energizada").

Numa reação térmica convencional (exotérmica), a energia absorvida pelo reagente, $\mathrm{R}_{0}$, é utilizada para modificar ligações nas moléculas envolvidas e o excesso de energia é dissipado em forma de calor. O mecanismo proposto envolve a formação de um complexo ativado $(\neq)$ através do aquecimento, ocorrendo posteriormente a formação da molécula do produto num estado vibracionalmente excitado, o qual dissipa seu excesso de energia através da liberação de calor (Figura 1- A) ${ }^{2}$.

Além da ativação térmica, as moléculas podem ser induzidas a reagir através de irradiação eletro-magnética num comprimento de onda apropriado. Conforme ilustrado na Figura 1- B, numa reação fotoquímica ("foto-energizada"), a molécula do reagente, $\mathrm{R}_{0}$, absorve um fóton resultando num estado eletronicamente excitado $R^{*}$, o qual utiliza a energia eletrônica adquirida para promover uma reação química. O produto gerado no seu estado fundamental, porém vibracionalmente excitado $\left(\mathrm{P}^{\ddagger}\right)$, ao dissipar seu excesso de energia, libera calor ${ }^{2}$.

Numa reação quimiluminescente (Figura 1 - C), o processo pode ser esquematizado da seguinte forma: o reagente no estado fundamental, $\mathrm{R}_{\mathrm{o}}$, adquire energia térmica suficiente para originar o complexo ativado $(\neq)$, o qual transforma-se no produto eletronicamente excitado $\left(\mathrm{P}^{*}\right)$. Neste caso, a exotermicidade favorável do processo quimio-energizado é uma condição necessária, mas não suficiente, para a formação do produto num estado eletronicamente excitado $\left(\mathrm{P}^{*}\right)^{2}$.
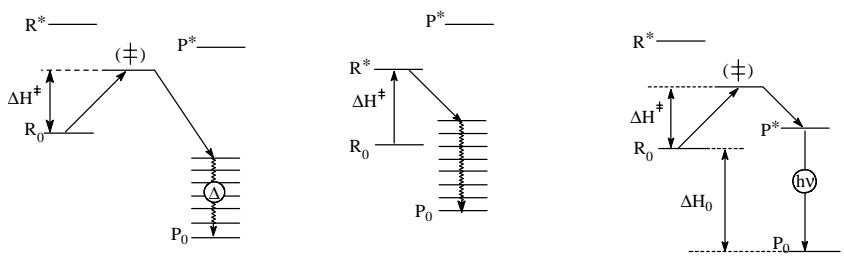

Figura 1. Diagramas de Níveis Energéticos para: A. Reação Térmica Exotérmica, B. Reação Fotoquímica ("foto-energizada") e C. Reação Quimiluminescente ("quimio-energizada"). 
Existem três modelos mecanísticos básicos para quimiluminescência em fase líquida: (i) a decomposição unimolecular de certas moléculas termodinamicamente instáveis, denominados 1,2-dioxetanos, (ii) a transferência de um elétron de um poderoso redutor para um oxidante e (iii) um mecanismo para quimiluminescência de certos peróxidos orgânicos em presença de hidrocarbonetos aromáticos policondensados, denominado "Chemically Initiated Electron Exchange Luminescence" (CIEEL) ${ }^{3}$.

No primeiro modelo descrito (Esquema 1), uma molécula de alto conteúdo energético sofre uma reação exotérmica, rearranjo ou fragmentação, gerando a molécula de produto num estado eletronicamente excitado. Se o estado excitado gerado é emissivo, observa-se emissão direta de quimiluminescência, caso contrário pode ocorrer a transferência de energia do estado excitado formado para uma molécula aceptora apropriada, resultando na emissão indireta de quimiluminescência. Entre os exemplos de reações quimiluminescentes, incluídos neste esquema geral, podemos citar a fragmentação unimolecular de 1,2-dioxetanos, o rearranjo do benzeno de Dewar e a clássica reação quimiluminescente do luminol ${ }^{3}$.

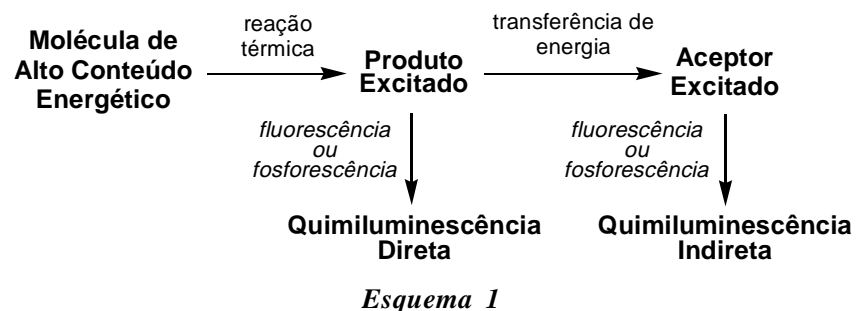

O segundo modelo geral para a produção de luz através de processos químicos, mostrado esquematicamente na Figura 2, é conhecido sob a denominação de quimiluminescência gerada eletroquimicamente ("Electrogenerated Chemiluminescence"ECL $)^{3,4}$. Segundo este mecanismo, uma molécula é reduzida no cátodo formando um ânion-radical e uma segunda molécula é oxidada no ânodo formando um cátion-radical. Os íons-radicais difundem-se através da solução e podem sofrer aniquilação. Considerações simples de orbitais moleculares predizem que esta aniquilação pode resultar na geração de um estado eletronicamente excitado, ou seja, pode ocorrer a transferência de um elétron do LUMO do ânion-radical de A para o LUMO do cátion-radical $\mathrm{B}$, processo este responsável pela geração do estado eletronicamente excitado de B (B*). Da mesma forma, pode ocorrer a transferência de elétron do HOMO do ânion-radical de A para o HOMO do cátion-radical de $\mathrm{B}$, o que resulta na formação de A num estado eletronicamente excitado $\left(\mathrm{A}^{*}\right)$. A eficiência da formação do estado eletronicamente excitado depende, entre outros fatores, da energética da transformação.

O terceiro mecanismo geral proposto para a geração de estados eletronicamente excitados, denominado CIEEL

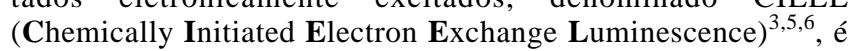
uma combinação dos dois previamente descritos (Esquema 2). Em resumo, a seqüência é iniciada pela transferência de um elétron de uma molécula doadora apropriada (ativador, ACT) para uma molécula orgânica de alto conteúdo energético (peróxido). Num passo subseqüente, ocorre um rearranjo ou perda de um fragmento neutro, transformando o peróxido reduzido numa espécie altamente redutora (ânion-radical). A aniquilação de carga gera o ativador (ACT) num estado eletronicamente excitado. Como no caso da quimiluminescência gerada eletroquimicamente (ECL), o processo de aniquilação dos radicais-íons é o verdadeiro responsável pela quimio-excitação, entretanto, no mecanismo CIEEL tais radicais são gerados quimicamente e não eletroquimicamente.

Recentemente, a bio e quimiluminescência têm provocado grande impacto em análises bioquímicas, biologia celular, medicina e biotecnologia. A identificação de diversas funções
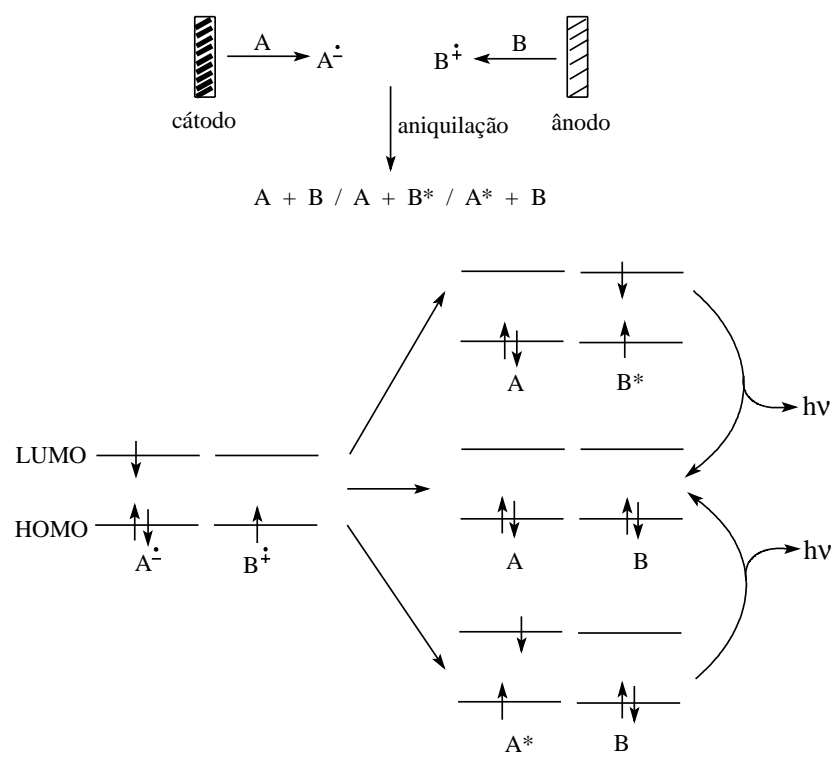

Figura 2. Representação esquemática da quimiluminescência gerada eletroquimicamente, mostrando somente a formação de estados eletronicamente excitados singlete, os quais levam à emissão de quimiluminescência, apesar de estados excitados triplete também poderem ser formados no processo de aniquilação.

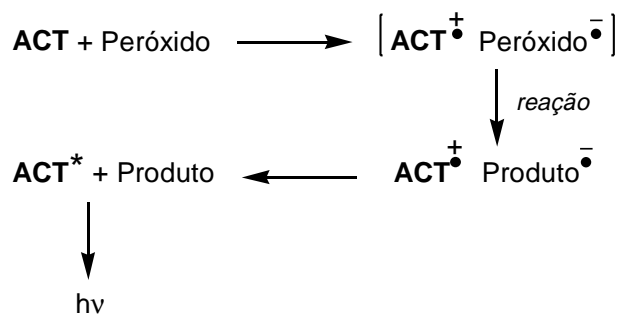

Esquema 2

biológicas, a classificação de reações bioluminescentes de diferentes organismos, a elucidação detalhada de um passo reacional, entre outros, são algumas das principais motivações para o estudo da bioluminescência ${ }^{3}$. O interesse em quimiluminescência deve-se, além do desafio acadêmico de desvendar o mecanismo, à marcante sensibilidade e freqüiente seletividade como ferramenta analítica. Como resultado, a quimiluminescência tem encontrado extensiva aplicação na detecção de traços de metais em solução ${ }^{7}$, de metabólitos e de uma série de substratos de enzimas ${ }^{8,9}$. O desenvolvimento de uma fonte portátil e comercial de "luz fria" é também um dos motivos pelo interesse em reações quimiluminescentes ${ }^{1}$.

\section{QUIMILUMINESCÊNCIA DE 1,2-DIOXETANOS}

1,2-Dioxetanos (1) são moléculas bastante intrigantes: alguns são extremamente instáveis, enquanto outros são estáveis por dias, meses ou até mesmo anos à temperatura ambiente. Além disso, quando aquecidos em solução, sofrem decomposição gerando dois compostos carbonílicos, um deles podendo ser formado em um estado eletronicamente excitado (eq. 1) ${ }^{10}$.

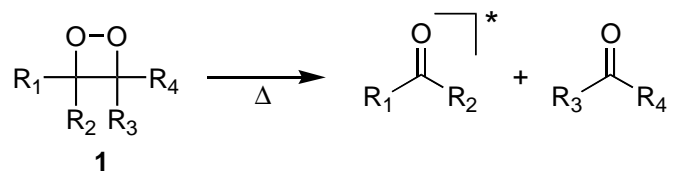


No início do século, mesmo antes de serem preparados e isolados, 1,2-dioxetanos (1) e $\alpha$-peróxilactonas (2) foram propostos como intermediários de certas reações de oxidação ${ }^{11}$. A proposta estrutural para estes compostos de alta energia, os quais foram posteriormente sugeridos como intermediários-chave em muitos sistemas bio e quimiluminescentes ${ }^{10}$, baseava-se nos seguintes fatos:

a. A clivagem térmica em dois fragmentos carbonílicos deveria ser muito exotérmica, considerando o relaxamento da tensão anelar e a formação de duas ligações fortes carbonílicas, às custas da quebra de uma ligação fraca $\mathrm{O}-\mathrm{O}$ e uma ligação $\mathrm{C}-\mathrm{C}$.

b. Na estrutura do dioxetano, o grupo $\mathrm{C}-\mathrm{O}$ está fora do plano de $\mathrm{R}_{1}-\mathrm{C}-\mathrm{R}_{2}$, como nos estados excitados de aldeídos e cetonas. Esta similaridade estrutural deveria favorecer a formação dos compostos carbonílicos no estado eletronicamente excitado (fator de Franck-Condon favorável) ${ }^{10}$.

c. Dois fragmentos carbonílicos são freqüentemente observados entre os produtos de reações bio e quimiluminescentes.

\section{DECOMPOSIÇÃO UNIMOLECULAR DE 1,2-DIOXETANOS}

O isolamento e a caracterização do primeiro dioxetano, o 3,3,4-trimetil-1,2-dioxetano (3), foi relatado em 1969 por Kopecky e Mumford ${ }^{12}$. Ao contrário das expectativas, este dioxetano apresentava certa estabilidade e, quando aquecido, sofria decomposição gerando acetona e acetaldeído como produtos, sendo observada uma fraca emissão de luz azulada ${ }^{10,12}$.

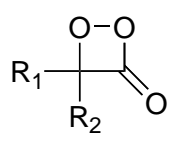

2

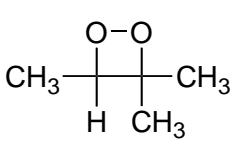

3
Apesar de passados mais de 25 anos desde a preparação do primeiro 1,2-dioxetano, estes peróxidos cíclicos de 4 membros, ricos em energia, ainda continuam a despertar a atenção de pesquisadores. Centenas de dioxetanos já foram sintetizados e estudados em solventes orgânicos na esperança de se entender porquê um dos fragmentos carbonílicos é formado num estado eletronicamente excitado, com rendimentos de quimiluminescência altos $\left(0,01 \text { e } 0,60 \mathrm{E} \mathrm{mol}^{-1}\right)^{13}$. A termólise de 1,2-dioxetanos, contendo substituintes simples (alquila, arila, alcoxila), leva à formação preferencial de produtos carbonílicos excitados triplete. Estados excitados singlete também são observados, porém com rendimentos muito baixos, provavelmente devido a questões energéticas ${ }^{14}$.

Até hoje não foi totalmente esclarecido o mecanismo operante na decomposição unimolecular de 1,2-dioxetanos contendo substituintes simples e, por isso, esses compostos continuam sendo alvo de investigações teóricas e experimentais ${ }^{15}$. A explicação para a formação preferencial de produtos excitados triplete e a influência de substituintes sobre a estabilidade do anel peroxídico são questões intimamente correlacionadas ao mecanismo de decomposição. Portanto, não é surpreendente que a elucidação deste complexo problema mecanístico tenha sido considerada uma meta de extrema importância desde a preparação do primeiro 1,2-dioxetano.

Três mecanismos: concertado ${ }^{16}$, concertado não-sincronizado $^{17,18}$ e birradicalar ${ }^{19-21}$, cada um deles baseado em dados experimentais convincentes, foram postulados para explicar a decomposição unimolecular destes compostos (Esquema 3).

Uma prova inequívoca do envolvimento de um birradical no mecanismo de decomposição poderia ser obtida caso um experimento simples de seqüestro fosse realizado com sucesso. Tais experimentos, inicialmente apresentados como conclusivos $^{22}$, na realidade não foram confirmados. Estudos posteriores indicaram que os produtos isolados seriam provenientes da decomposição induzida do dioxetano pelo seqüestrador e não do seqüestro de um birradical intermediário ${ }^{23,24}$. Já no caso do mecanismo concertado, embora capaz de explicar os altos rendimentos de produtos excitados, a forma simples de sua concepção não fornece ferramentas adequadas para explicar as altas relações triplete/singlete $\left(\Phi^{\mathrm{T}} / \Phi^{\mathrm{S}}\right)$ observadas. $\mathrm{O}$ mecanismo concertado não sincronizado, onde a quebra da ligação O-O é mais avançada do que a quebra da ligação C-C, parece o mais adequado para elucidar o mecanismo de decomposição unimolecular de 1,2-dioxetanos. Este mecanismo, chamado de "mesclado" (merged) ${ }^{18}$ é compatível com todos os resultados experimentais obtidos até o momento, pois não foi possível a detecção de intermediários birradicalares na decomposição de 1,2-dioxetanos e, mais importante, com a utilização deste mecanismo, os altos rendimentos triplete e os efeitos da estrutura dos compostos sobre estes rendimentos podem ser explicados adequadamente ${ }^{2,14,18,25}$. Além disso, resultados

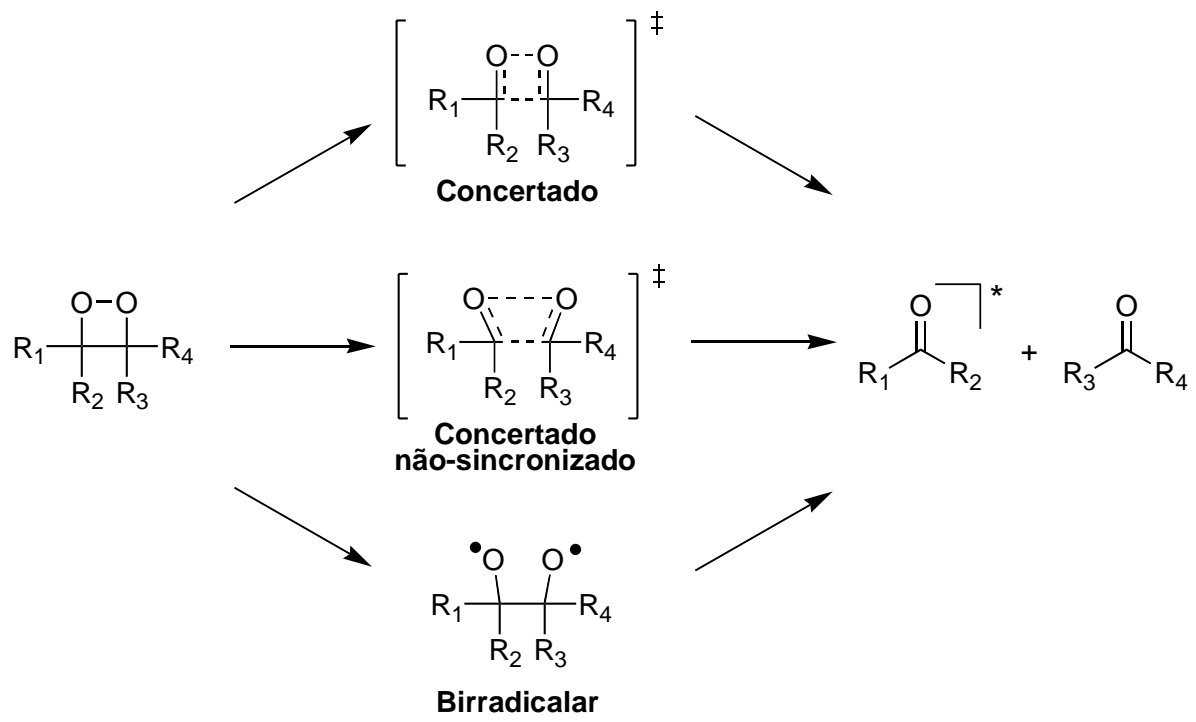

Esquema 3 
recentes de cálculos teóricos são compatíveis com esta interpretação mecanística, apesar do fato das conclusões dos autores deste trabalho parecerem ser contrárias ${ }^{15}$. Porém esta discrepância parece ser somente uma questão de nomenclatura mecanística.

\section{DECOMPOSIÇÃO CATALISADA DE PERÓXIDOS}

Normalmente, em soluções à temperatura ambiente, não se observa emissão de fosforescência, pois espécies excitadas triplete possuem tempos de vida longos, podendo ser desativadas antes que emitam. Em soluções contendo dioxetanos observa-se uma fraca emissão de luz pois, não só a formação de produtos carbonílicos no estado excitado singlete é, geralmente, baixa, como também a eficiência de fluorescência destes, é pequena. Partindo-se deste ponto de vista, dioxetanos podem ser considerados modelos inadequados para a elucidação de processos bioluminescentes intensos, onde é necessária a formação de espécies excitadas singlete com altos rendimentos quânticos.

A emissão fraca de luz, observada na decomposição de 1,2-dioxetanos, pode ser realçada através da utilização de aceptores da energia de excitação: compostos com bons rendimentos quânticos de fluorescência, especialmente na região do visível ${ }^{3,10}$. Esta intensificação de emissão de luz ocorre devido a um processo de transferência de energia. Se os produtos eletronicamente excitados de uma reação possuem baixos rendimentos quânticos de fluorescência ou fosforescência, a transferência de energia a partir desses produtos excitados para o aceptor pode resultar numa amplificação da intensidade de emissão de várias ordens de grandeza (eq. 2). Estes aceptores de energia não participam da reação de decomposição do peróxido e, conseqüentemente, não alteram a velocidade desta decomposição.

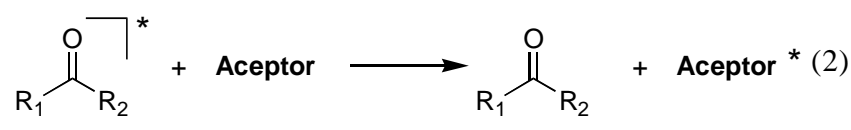

\section{Catálise Intermolecular}

A quimiluminescência de $\alpha$-peroxilactonas (2), entretanto, permite uma melhor representação do processo de bioluminescência, pois tais compostos são propostos como precursores de espécies emissoras na reação bioluminescente de vários sistemas.

Schuster ${ }^{5,6,27}$ demonstrou que alguns peróxidos, como por exemplo o difenoilperóxido (4) (eq. 3) e a 3,3-dimetil-1,2dioxetanona (6) (eq. 4$)^{6,27,28}$, podiam reagir com determinados aceptores (hidrocarbonetos aromáticos - ACT) através de uma reação direta bimolecular, levando à formação destes últimos num estado excitado singlete, sem que houvesse a intervenção de um passo de transferência de energia. A quimiluminescência do feniletil-peróxi-acetato (7), levando à formação quantitativa de ácido acético e acetofenona (eq. 5), também apresenta comportamento semelhante à 4 e $\mathbf{6}^{56}$. Em todos os casos foi constatado que, tanto a velocidade de decomposição do peróxido quanto a intensidade de emissão aumentavam em presença do aceptor, o qual não era consumido durante o processo. Além disso, também a velocidade de decomposição dependia do potencial de oxidação e da concentração do ativador (ACT), e que a emissão observada era devida à fluorescência do mesmo $\left({ }^{1} \mathrm{ACT}\right)$. $\mathrm{O}$ conjunto de dados mostrava estar envolvido um caminho de reação no qual um processo de transferência de elétron, ou de carga, desempenhava um papel crítico. O mecanismo CIEEL (Chemically Initiated Electron Exchange Luminescence, ou seja luminescência induzida quimicamente pela troca de elétron), proposto por Schuster ${ }^{5,6}$ no final da década de 70 , oferece uma boa explicação para as propriedades observadas.
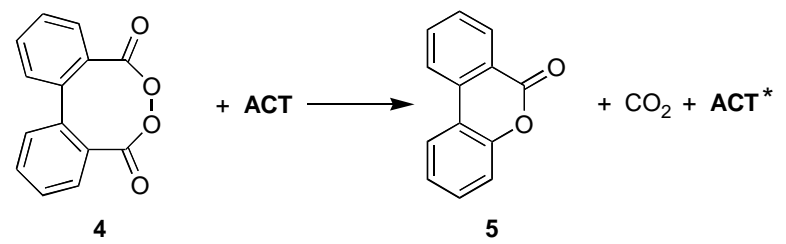

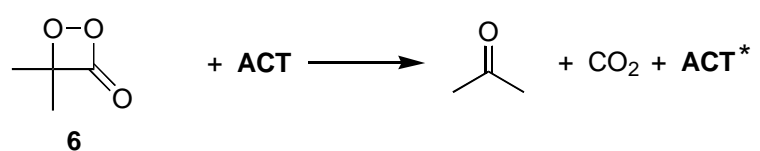

$$
\underset{\mathrm{H}_{3} \mathrm{C}}{\mathrm{Ph}} \underset{7}{\mathrm{H}} \underset{\mathrm{O}}{\mathrm{H}_{3} \mathrm{C}}=\mathrm{O}+\mathrm{ACT} \longrightarrow \mathrm{Ph}_{\mathrm{CH}_{3}}^{\mathrm{O}}+\mathrm{CH}_{3} \mathrm{CO}_{2} \mathrm{OH}+\mathbf{A C T} \text { * }
$$

Todavia, na decomposição do difenoilperóxido (4), primeiro exemplo de quimiluminescência induzida quimicamente pela transferência de elétron (CIEEL), os altos rendimentos de quimiluminescência relatados por Schuster ${ }^{5}, \Phi_{\mathrm{CHL}}=0,1 \mathrm{E} \mathrm{mol}^{-1}$, não foram confirmados, sendo posteriormente re-determinados, apresentando valores da ordem de $10^{-4} \mathrm{E} \mathrm{mol}^{-1}$, ou seja, menores em quatro ordens de grandeza ${ }^{29}$.

\section{Catálise Intramolecular}

Um exemplo clássico de decomposição intramolecular envolvendo peróxidos cíclicos é o processo de bioluminescência do vaga-lume, onde uma $\alpha$-peroxilactona é proposta como intermediário responsável pela emissão de luz. A oxidação catalisada por luciferase da luciferina ${ }^{* *}$ do vaga-lume ${ }^{8}$, a qual possui um núcleo constituído pelo grupo benzotiazol, ocorre através da formação do intermediário 9 (Esquema 4). White ${ }^{30}$ descreveu o efeito de vários substituintes no processo de bioluminescência in vitro da luciferina do vaga-lume. Foi observado que, apesar de 8a-e sofrerem oxidação gerando as correspondentes oxiluciferinas 10a-e, apenas no caso da luciferina natural 8a e da aminossubstituída 8c ocorria o processo de bioluminescência (Esquema 4).

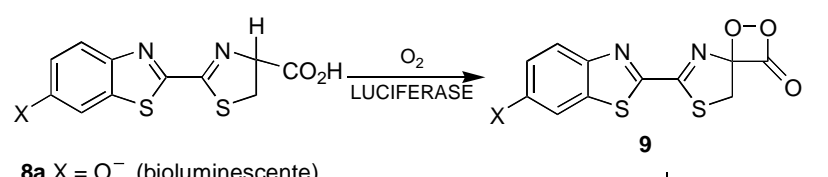

$$
\begin{aligned}
8 \mathbf{X} X & =\mathrm{O}^{-} \text {(bioluminescente) } \\
\mathbf{b} \mathrm{X} & =\mathrm{OCH}_{3} \\
\mathbf{c} \mathrm{X} & =\mathrm{NH}_{2}(\text { bioluminescente) } \\
\mathbf{d X} & =\mathrm{NHCOCH}_{3} \\
\text { e X } & =\mathrm{NHCOCF}_{3}
\end{aligned}
$$

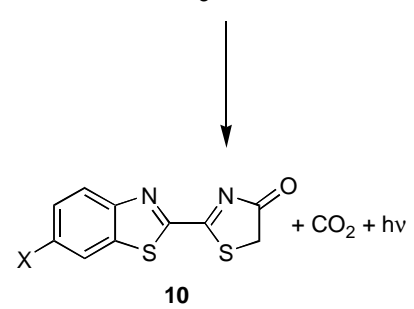

Esquema 4

Tais observações foram atribuídas a uma transferência "interna" de elétrons dos substituintes doadores $\left(\mathrm{O}^{-} \mathrm{e} \mathrm{NH}_{2}\right)$ para o anel dioxetânico, gerando, após descarboxilação, as respectivas oxiluciferinas $\mathbf{1 0} \mathrm{com}$ altos rendimentos de espécies excitadas singlete.

\footnotetext{
**Segundo a terminologia utilizada para bioluminescência, as enzimas são denominadas luciferases e os substratos luciferinas. Estes são termos genéricos que não implicam na identidade de enzimas e substratos entre os diferentes organismos bioluminescentes.
} 
Dioxetanos contendo substituintes "simples", tais como: grupos alquila, alcoxila, acila ou arila, sofrem termólise somente segundo o mecanismo unimolecular (eq. 1), não existindo dados na literatura sobre a ocorrência de um mecanismo CIEEL intermolecular nestes $\operatorname{casos}^{24 a}$. Entretanto, quando o anel peroxídico contém substituintes doadores de elétron, tais compostos tornam-se mais lábeis, sofrendo decomposição segundo o mecanismo CIEEL intramolecular, em analogia ao processo proposto para a bioluminescência do vaga-lume. Exatamente nestes casos a extensão da hipótese CIEEL torna-se mais interessante, pois fornece uma explicação imediata para os altos rendimentos de produtos excitados singlete em muitos sistemas bioluminescentes.

Entre os exemplos de decomposição de dioxetanos catalisada por transferência intramolecular de elétron podemos citar o trabalho de McCapra descrevendo a síntese e propriedades quimiluminescentes de derivados de 9-alquilideno-10-metilacridinas $(\mathbf{1 1})^{31}$.

Entre os compostos sintetizados, apenas 11b pôde ser isolado, devido ao padrão apropriado de substituição, pois o substituinte adamantila proporciona maior estabilidade ao anel peroxídico. Os demais eram muito instáveis $\left(t_{1 / 2} \cong 8 \mathrm{~min}, 25\right.$ ${ }^{\circ} \mathrm{C}$ ) e foram detectados somente através de $\mathrm{RMN}-{ }^{1} \mathrm{H}$. Além disso, em contraste com as propriedades normalmente observadas na decomposição de 1,2-dioxetanos, onde as espécies excitadas geradas são predominantemente tripletes, os rendimentos obtidos de espécies excitadas singlete nas decomposições de 11a, 11b e 11c eram consideráveis: $0,25,0,12$ e $0,059 \mathrm{E} \mathrm{mol}^{-1}$, respectivamente (Esquema 5). McCapra associou os altos rendimentos de estados excitados singlete gerados de $N$-metilacridona (12) ao mecanismo de decomposição induzido pela transferência de elétron, reiterando, numa comunicação concisa ${ }^{32}$, sua audaciosa sugestão para o mecanismo de quimiluminescência da reação peróxi-oxalato, proposta 4 anos antes ${ }^{33}$. Lee e Singer ${ }^{34}$, analisando diferentes substituintes em 11, reforçaram a proposta de que a decomposição ocorria via íons-radicais, sendo o processo de excitação resultado de uma transferência intramolecular de elétron (CIEEL Intramolecular).<smiles>[R7]C1([R7])OOC12c1ccccc1N(C)c1ccccc12</smiles>

11

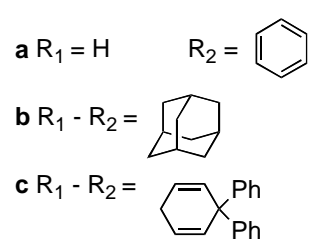<smiles>Cn1c2ccccc2c(=O)c2ccccc21</smiles><smiles>[R7]C([O-])[18O]CC</smiles><smiles>[R7]C(=O)[PH2+]c1ccc2c(=O)c3ccccc3n(C)c2c1</smiles>

12
Esquema 5

Os estudos das propriedades do 1-(1-metil-3-indolil)-6-fenil2,5,7,8-tetraoxabiciclo[2.4.0]-1,2-dioxetano (13), composto este muito instável, revelaram mais um exemplo de CIEEL intramolecular $^{35}$. Neste caso, o substituinte $\beta$-indolila apresenta duas propriedades fundamentais para ocorrência e observação do mecanismo CIEEL intramolecular: é bom doador de elétron e fortemente fluorescente. Em solventes apolares, o espectro de quimiluminescência mostrava apenas um pico $(320 \mathrm{~nm})$, coincidente com o espectro de fluorescência do produto (diéster). Entretanto, em solventes polares, um segundo pico de emissão aparecia em um comprimento de onda mais longo $(400 \mathrm{~nm})$, o que foi atribuído à formação de um exciplexo (complexo de transferência de carga no estado excitado) estabilizado pelo solvente.

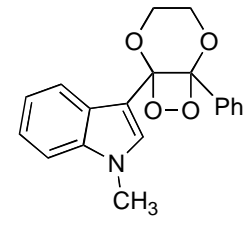

13

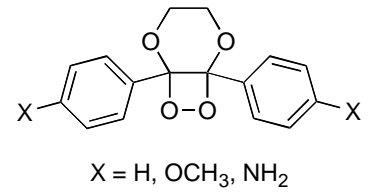

14
Idéias muito similares foram propostas por Schaap e colaboradores para explicar a instabilidade de dioxetanos derivados de 1,6-diaril-2,5,7,8-tetraoxabiciclo[2.4.0]octanos (14), quando substituídos por grupos facilmente oxidáveis tais como $\mathrm{NH}_{2}{ }^{36}$. Foi observado que a facilidade de oxidação do substituinte aromático influenciava fortemente tanto a estabilidade quanto os rendimentos de quimiluminescência de 14. Quando $X=H$ ou $\mathrm{X}=\mathrm{OMe}$, a estabilidade dos compostos era comparável à de 1,2-dioxetanos simples e as espécies excitadas formadas eram predominantemente tripletes. Entretanto, quando X era um grupo facilmente oxidável, 14 tornava-se substancialmente desestabilizado e sua decomposição gerava estados excitados singlete com altos rendimentos. O comportamento de $\mathbf{1 4}$ era bastante semelhante ao de alguns sistemas bioluminescentes conhecidos e o mecanismo proposto para explicar tais observações envolvia a transferência intramolecular de elétron.

Utilizando um padrão de substituição muito semelhante a 14, o estudo de dioxetanos derivados de 1,6-diaril-2,5,7,8-tetraoxabiciclo[2.4.0]octanos $(\mathbf{1 5})^{37}$ foi de relevante importância para a elucidação do processo de bioluminescência do vaga-lume. Os dioxetanos 15a e 15b apresentavam comportamento semelhante a dioxetanos simples: eram relativamente estáveis $\left(\mathrm{t}_{1 / 2} \cong 2-3\right.$ dias, $25^{\circ} \mathrm{C}$ ) e, quando decompostos sob aquecimento, davam origem a produtos carbonílicos excitados triplete (Esquema 6). Entretanto, quando $15 \mathrm{~b}$ era desprotonado, resultando no dioxetano fenoxissubstituído 15c, suas propriedades mudavam drasticamente. O comportamento então observado era análogo ao do intermediário proposto no mecanismo de bioluminescência do vaga-lume (9a, Esquema 4). Enquanto $\mathbf{1 5 b}$ possuía um tempo de meia-vida $\left(\mathrm{t}_{1 / 2}\right)$ de aproximadamente 17 anos a $-30{ }^{\circ} \mathrm{C}$, ao ser tratado com base a esta temperatura, gerando $15 \mathbf{c}$, podia-se observar imediatamente um relâmpago de luz brilhante azulada ${ }^{37}$.

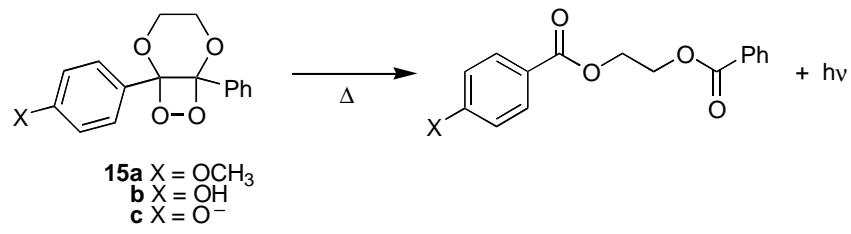

Esquema 6

No final da década de 80 , Schaap divulgou os resultados obtidos a partir do estudo das propriedades de um composto termicamente estável, cuja decomposição podia ser iniciada instantaneamente através de uma reação química ${ }^{38-40}$. Entre os compostos preparados e estudados, 1,2-dioxetanos contendo como substituintes os grupos espiroadamantila e $t$-butildimetilsililoxiarila, por exemplo, os compostos 16, apresentavam alta estabilidade térmica $\left(\mathrm{t}_{1 / 2} \cong 3\right.$ anos, $\left.25{ }^{\circ} \mathrm{C}\right)$ devido à presença do substituinte adamantila, estericamente impedido. Todavia, se o 
grupo protetor era removido, a decomposição tornava-se extremamente rápida e os rendimentos de quimiluminescência muito altos (cerca de $\left.0,20 \mathrm{E} \mathrm{mol}^{-1}\right)^{38}$, o que corresponde a um rendimento de espécies excitadas singlete de aproximadamente 0,50 $\mathrm{E} \mathrm{mol}^{-1} 38$. A alta estabilidade, associada aos altos rendimentos de quimiluminescência observados em presença de um catalisador tornaram possível a utilização de tal classe de compostos em imunoensaios (vide Aplicações Analíticas de 1,2-Dioxetanos).

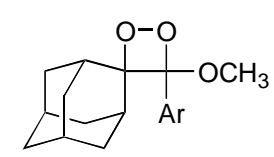

16

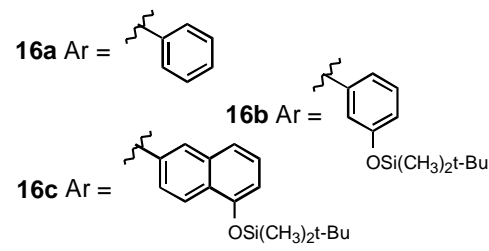

Devido à vasta gama de aplicações analíticas de 16, a procura por sistemas alternativos tem sido uma preocupação constante entre a comunidade científica da área. Entre os exemplos podemos citar 1,2-dioxetanos contendo como substituinte o grupo benzofurano $(\mathbf{1 7})^{41,42}$. Os estudos das propriedades quimiluminescentes revelaram a ocorrência do mecanismo CIEEL na decomposição induzida por base de $\mathbf{1 7 a}^{41}$ e por fluoreto de $\mathbf{1 7} \mathbf{b}^{42}$. Além disso, foi observado que os isômeros meta-substituídos apresentavam maiores rendimentos de quimiluminescência $\left(\Phi_{\text {CIEEL }}\right)$, quando comparados aos para- e orto-substituídos, todavia a eficiência de emissão de luz $\left(\Phi_{\mathrm{CIEEL}} \cong 10^{-7} \mathrm{E}\right.$ $\mathrm{mol}^{-1}$ ) era significativamente inferior àquela observada para a decomposição catalisada de $\mathbf{1 6}$.

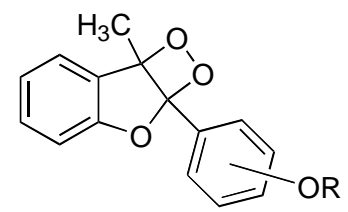

17

$17 \mathrm{a} R=\mathrm{OAC}$

17b $\mathrm{R}=\mathrm{OSi}\left(\mathrm{CH}_{3}\right)_{2} \mathrm{t}-\mathrm{Bu}$

Nesta mesma linha de pesquisa, Adam e colaboradores ${ }^{43}$ relataram a preparação e as propriedades quimiluminescentes de 1,2-dioxetanos 18 contendo como substituinte o grupo indolina $\mathrm{N}$-acetilado. Em contraste com os 1,2-dioxetanos contendo o substituinte indolina "desprotegido" (grupo $\mathrm{NH}$ livre), os quais são bastante lábeis, tais compostos são mais estáveis, pois o substituinte $\mathrm{N}$-alcoxicarbonila reduz a densidade eletrônica sobre o átomo de nitrogênio, podendo ser isolados em coluna cromatográfica a baixas temperaturas. Porém, a entalpia de ativação determinada para a termólise de $18\left(19,3 \mathrm{kcal} \mathrm{mol}^{-1}\right)$ é aproximadamente $4 \mathrm{kcal} \mathrm{mol}^{-1}$ inferior aos valores normalmente obtidos para a decomposição unimolecular de 1,2-dioxetanos. Os rendimentos quânticos triplete são significativamente superiores aos singlete $\left(\Phi^{\mathrm{T}} / \Phi^{\mathrm{S}} \cong 40\right)$, como normalmente observado para dioxetanos simples. Entretanto, a presença de íons fluoreto induz à rápida decomposição de $\mathbf{1 8}$ com apreciável emissão de luz, consideravelmente superior àquela observada na decomposição térmica (Esquema 7).

Porém, em analogia aos resultados obtidos para 17, os rendimentos de quimiluminescência da decomposição catalisada por íons fluoreto de 18 foram extremamente baixos $\left(\Phi_{\mathrm{CHL}}=310^{-9}\right.$ $\mathrm{E} \mathrm{mol}^{-1}$ ) o que, aliado à baixa estabilidade do composto protegido (acilado) torna inviável sua utilização em imunoensaios quimiluminescentes.

Recentemente, foram descritas a síntese e as propriedades quimiluminescentes dos dioxetanos 19 a $\mathbf{2 1}^{44,45}$. A decomposição

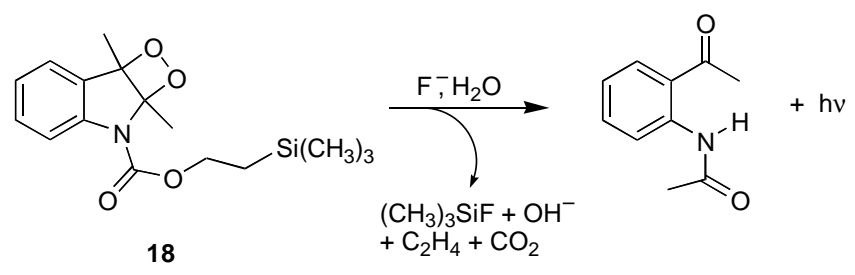

Esquema 7

de 19 e 20, nos quais o grupo fenolato protegido é conectado ao anel peroxídico através de grupos etenila e etinila, respectivamente, leva a uma emissão avermelhada $\left(\lambda_{\operatorname{máx}} \sim 630 \mathrm{~nm}\right) \mathrm{com}$ rendimentos de quimiluminescência de $2,6 \times 10^{-4}$ e $3,0 \times 10^{-7}$ $\mathrm{E} \mathrm{mol}^{-1}$, respectivamente ${ }^{44}$. Os 1,2-dioxetanos 21, análogos dos derivados 16 com o grupo adamantila substituído por dois grupos isopropila mostram decomposição induzida acompanhada de uma intensa emissão azulada $\left(\lambda_{\text {máx }}=470 \mathrm{~nm}\right)$ com rendimentos de quimiluminescência altos (até $\left.0.2 \mathrm{E} \mathrm{mol}^{-1}\right)^{45}$.

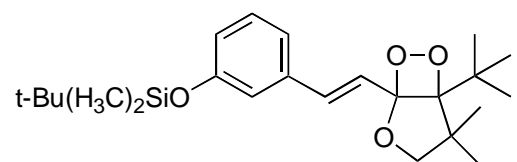

19
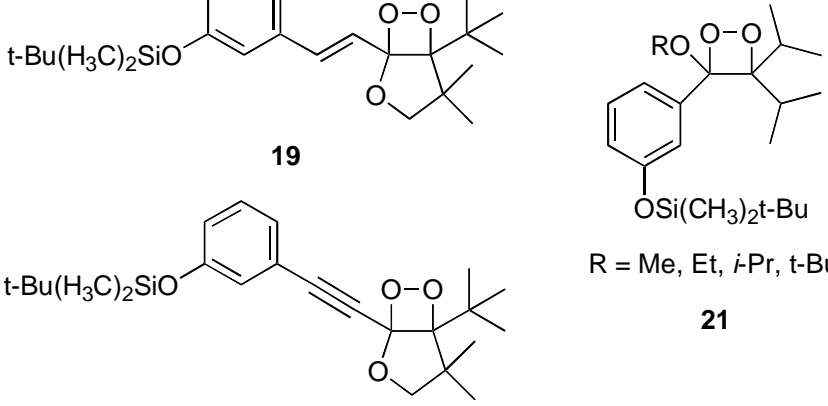

$\mathrm{R}=\mathrm{Me}, \mathrm{Et}, i-\operatorname{Pr}, \mathrm{t}-\mathrm{Bu}$

21

20

Analisando os trabalhos sobre a decomposição intramolecular via CIEEL de 1,2-dioxetanos, percebe-se claramente que a grande maioria das iniciativas baseia-se na busca por dioxetanos similares a 16, por ser este o modelo ideal até o momento para a utilização em imunoensaios. Procuram-se basicamente compostos que apresentem estabilidade térmica alta e cuja decomposição possa ser induzida quimicamente ou via catálise enzimática, gerando altos rendimentos de quimiluminescência. Todavia, a grande maioria dos exemplos estudados até o momento apresenta baixos rendimentos de quimiluminescência.

\section{Aplicações Analíticas de 1,2-Dioxetanos}

Em química clínica, a maioria dos compostos de interesse está presente no organismo em concentrações tão baixas que normalmente não pode ser detectada através de métodos analíticos comuns. Entre os métodos de detecção de alta sensibilidade mais comuns pode-se citar a utilização de nuclídeos radioativos, tais como ${ }^{32} \mathrm{P}$ ou ${ }^{35} \mathrm{~S}$. Todavia devido a problemas comumente associados à sua utilização, tais como, danos à saúde, problemas de descarte, tempos de meia-vida, vários marcadores não-isotópicos, utilizando-se principalmente técnicas quimiluminescentes, vêm sendo desenvolvidos ${ }^{46}$.

Dioxetanos são utilizados principalmente para a detecção e quantificação quimiluminescente de sequiências específicas de DNA e RNA através do procedimento originalmente desenvolvido por Southern, denominado "Southern blotting". A técnica envolve a transferência de fragmentos de DNA, separados por eletroforese, de um gel para uma membrana suporte, seguida de hibridização com uma sonda marcada. A membrana é, então, lavada e a sequiência de interesse detectada através da emissão de quimiluminescência observada para uma câmara fotográfica sensível. 
O dioxetano AMPPD, cuja estrutura é semelhante a 16, porém com a substituição do grupo protetor silila pelo fosfato, o qual pode ser removido através da ação da fosfatase alcalina (AP), foi responsável pelos avanços alcançados no desenvolvimento de uma nova geração de métodos simples, rápidos e ultra-sensíves de análises de DNA. O uso de marcadores enzimáticos, combinado a um método de detecção luminescente ultra-sensível constitui a base da utilização de AMPPD como substrato no sistema de detecção de DNA desenvolvido pela Tropix Inc., denominado "Southern Light" (Figura 3) e apresentado como alternativa à utilização de nuclídeos radioativos ${ }^{48}$.

O AMPPD incorpora várias funções importantes, entre elas, a estabilidade térmica $\left(\mathrm{t}_{1 / 2} \cong 1,2\right.$ anos, $\left.30{ }^{\circ} \mathrm{C}, \mathrm{pH}=12\right)$, facilidade de obtenção e a presença de um sítio de ativação devido ao substituinte fosfato, o qual pode ser clivado através da ação de uma enzima apropriada.

O procedimento para a execução do "Southern Light" é relativamente simples e não requer equipamentos especiais (Figura 3). Inicialmente, o fragmento de DNA a ser estudado é clivado por uma endonuclease. Os fragmentos clivados são então separados por eletroforese através de uma membrana gelatinosa. Em seguida, após desnaturação, as fitas simples de DNA são transferidas para uma superfície de náilon. A seguir, uma fita simples de DNA marcada com biotina, de seqüência conhecida, é adicionada à membrana e incubada, com a finalidade de permitir a re-hibridização. Após incubação, a membrana é lavada para retirar os fragmentos que não sofreram hibridização. Sobre a membrana é então adicionado um reagente denominado
AVIDX-AP (proteína avidina conjugada à enzima fosfatase); a avidina é uma proteína com forte afinidade pela biotina, marcador do DNA. Finalmente, adiciona-se solução de AMPPD. Caso tenha ocorrido re-hibridização, a fosfatase deve desencadear o processo de decomposição deste último e a emissão de luz observada pode ser projetada num filme fotográfico ${ }^{48}$. A emissão é intensa e pode durar até 30 minutos, pois o $t_{1 / 2}$ do ânion AMPD varia de 2 a $30 \mathrm{~min}$, dependendo das condições utilizadas.

O mecanismo proposto para a decomposição quimiluminescente de AMPPD envolve, em um primeiro passo, a desfosforilação provocada pela ação da fosfatase alcalina, gerando um ânion instável (AMPD). A seguir ocorre a transferência de elétron do fenolato gerado para o anel peroxídico e a clivagem deste último. Finalmente ocorre a retro-transferência de elétron, processo este responsável pela formação de espécies eletronicamente excitadas.

Além da detecção e quantificação de seqüências específicas de DNA e RNA, o teste também pode ser utilizado para a detecção de fosfatase alcalina (sensibilidade: $10^{-20}$ mols na membrana) ${ }^{49}$, sondas de ácidos nucleicos e outros ligantes. Além disso, através desta técnica, foi possível o desenvolvimento de métodos de detecção de vários organismos como o Vírus I da Herpes simplex $^{50}$, o Vírus da Hepatite $\mathrm{B}^{51}$, a Chlamydia trachomatis ${ }^{52}$, além de testes imunológicos do tipo ELISA. A tirotropina ${ }^{53}$, um hormônio estimulante da tireóide, a $\alpha$-fetoproteína ${ }^{54}$, monitorada em diagnósticos de pré-natal, e a $\beta$-galactosidase ${ }^{55}$ podem ser quantificadas através destes imunoensaios.

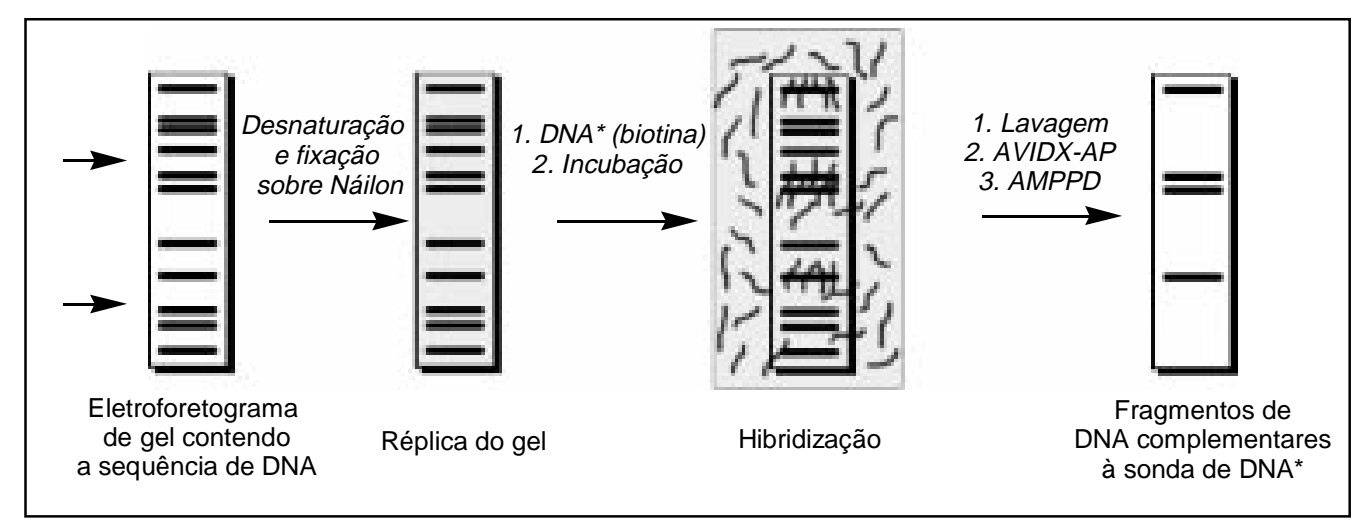<smiles>[R6]Oc1cccc(C(O)(OC)C2(OO)C3CC4CC(C3)CC2C4)c1</smiles>

AMPPD<smiles>COC1(c2cccc([O-])c2)OOC1(C1CC2CCC1C2)C1CC2CCC1C2</smiles>

AMPD<smiles>COC(=O)c1cccc([O-])c1</smiles>

Figura 3. Teste "Southern Light" Utilizado no Sequenciamento de DNA. 


\section{Abordagem Mecanística}

Segundo a nomenclatura adotada por Schuster, reações quimiluminescentes podem ser classificadas em três tipos básicos: (i) quimiluminescência direta - quando o emissor é um produto da reação (eq. 1), (ii) quimiluminescência indireta - quando o emissor é excitado via transferência de energia por um produto excitado (eq. 2), (iii) quimiluminescência ativada - quando uma reação direta bimolecular entre um peróxido rico em energia e um aceptor (o qual passa a ser chamado, neste caso, ativador: ACT, pois, como o próprio nome diz, ativa a decomposição do peróxido) leva à formação deste último num estado eletronicamente excitado via um novo caminho de reação. O processo pode ocorrer tanto intermolecularmente (eq. 3 e eq. 4$)^{56}$ quanto intramolecularmente; neste último caso a molécula do ativador é um substituinte do peróxido com baixo potencial de redução.

O mecanismo CIEEL intermolecular, observado no processo de quimiluminescência ativada da 3,3-dimetil-1,2dioxetanona (6) é análogo àquele inicialmente proposto para a decomposição do difenoilperóxido $(\mathbf{4})^{5,6}$. Em um primeiro passo, o ativador (ACT) e $\mathbf{6}$ formam um complexo de encontro (Esquema 8). Quando 6 é ativada termicamente, a ligação fraca O-O é alongada, a energia do orbital localizado anti-ligante mais baixo decresce e, como resultado, a afinidade eletrônica aumenta até o ponto onde a transferência de um elétron do ativador para o peróxido torna-se energeticamente viável $\left(\mathrm{k}_{\mathrm{ET}}\right.$ - "electron transfer"). A energia requerida para se atingir este ponto é menor do que aquela envolvida na quebra da ligação $\mathrm{O}-\mathrm{O}$ ou na formação do cátion-radical do ativador isolado. A transferência de um elétron do ativador para o peróxido ocorre, provavelmente, concomitantemente com a quebra total da ligação O-O. Esse processo dispara uma série de eventos em cascata: a ruptura da ligação C-C e liberação de $\mathrm{CO}_{2}$, ocorrendo a formação de um par de íons-radicais (cátion-radical de ACT e ânion-radical da acetona) em contato dentro da gaiola de solvente. A finalização da sequiência ocorre no momento em que as cargas desse par de íons-radicais sofrem aniquilação (kET - "back-electron transfer"), processo este que libera energia suficiente para gerar o ACT no seu primeiro estado excitado singlete (Esquema 8). Como todos esses eventos são extremamente rápidos, os íons-radicais permanecem em contato e mantêm por isso a "memória de spin", podendo ser comparados a um birradical singlete. Como conseqüência, o ACT deve ser formado no seu estado excitado singlete, sendo que a inversão de spin do par de íons-radicais do estado singlete para o triplete ocorre, aparentemente, de maneira mais lenta do que a sequiência de clivagem da ligação e aniquilamento por retrotransferência de elétron ${ }^{3}$. Esta interpretação é apoiada pela observação experimental da formação exclusiva de estados excitados singlete do ACT em todos os sistemas nos quais foi postulada a ocorrência do mecanismo CIEEL CI-6,25-29. $^{3}$.
No caso da decomposição de dioxetanos via o mecanismo CIEEL intramolecular, nota-se que a busca por novas estruturas de "estados eletronicamente excitados mascarados" em forma de compostos relativamente estáveis, como o AMPPD, continua sendo intensa ${ }^{57}$. Todavia, as abordagens visam principalmente altos rendimentos de quimiluminescência e especificidades enzimáticas, sendo raros os trabalhos relacionados a abordagens mecanísticas, alguns deles relatados a seguir.

Trofimov e colaboradores ${ }^{58}$, investigando a cinética e a formação de estados eletronicamente excitados na decomposição induzida por fluoreto dos dioxetanos termicamente estáveis, 16b e 22, observaram que o substituinte cloreto não alterava o passo de desproteção $\left(\mathrm{k}_{2}\right)$, mas aumentava cerca de cinco vezes a constante de velocidade de clivagem $\left(\mathrm{k}_{3}\right)$ (Esquema 9). Os rendimentos de quimio-excitação determinados foram os mesmos para ambos os dioxetanos $\left(\Phi_{\text {CIEEL }} \sim 0,3 \mathrm{E} \mathrm{mol}^{-1} \mathrm{em}\right.$ DMSO e $0,11 \mathrm{E} \mathrm{mol}^{-1}$ em $\left.\mathrm{CH}_{3} \mathrm{CN}\right)$. Foram estimadas as energias dos estados excitados triplete e singlete do fenolato $\mathbf{2 3}$, responsável pela emissão. Tais cálculos indicaram que, tanto estados excitados singlete quanto triplete, de caráter $\pi-\pi^{*}$, poderiam ser formados, embora apenas os primeiros fossem de fato observados no processo induzido por fluoreto.
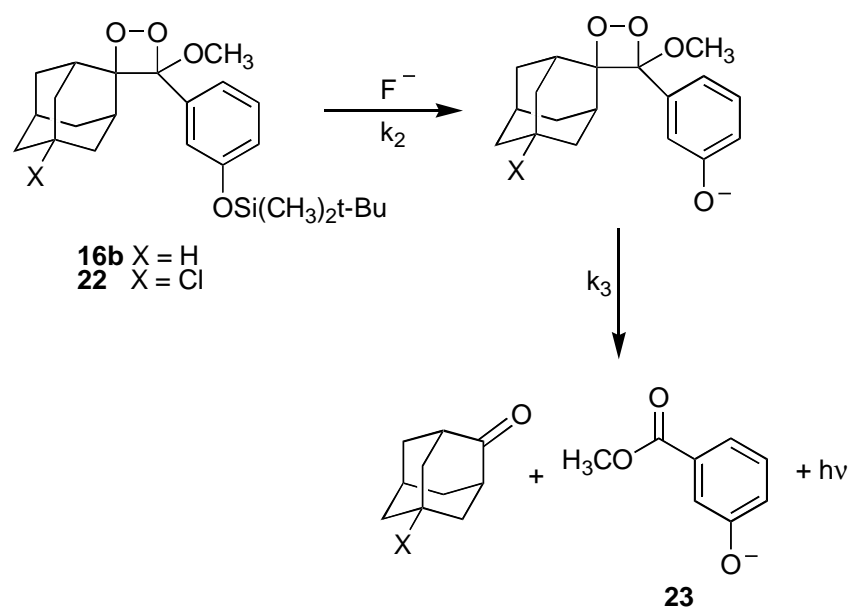

Esquema 9

O derivado análogo a $\mathbf{2 2}$, contendo o substituinte fosfato como grupo protetor, CSPD, reage de forma similar a AMPPD, todavia produzindo uma maior intensidade de luz e um intervalo mais curto para se atingir o estado estacionário ${ }^{59}$, características estas responsáveis pela sua extensiva utilização em ensaios quimiluminescentes.

Dados experimentais da dependência do $\mathrm{pH}$ e da eficiência

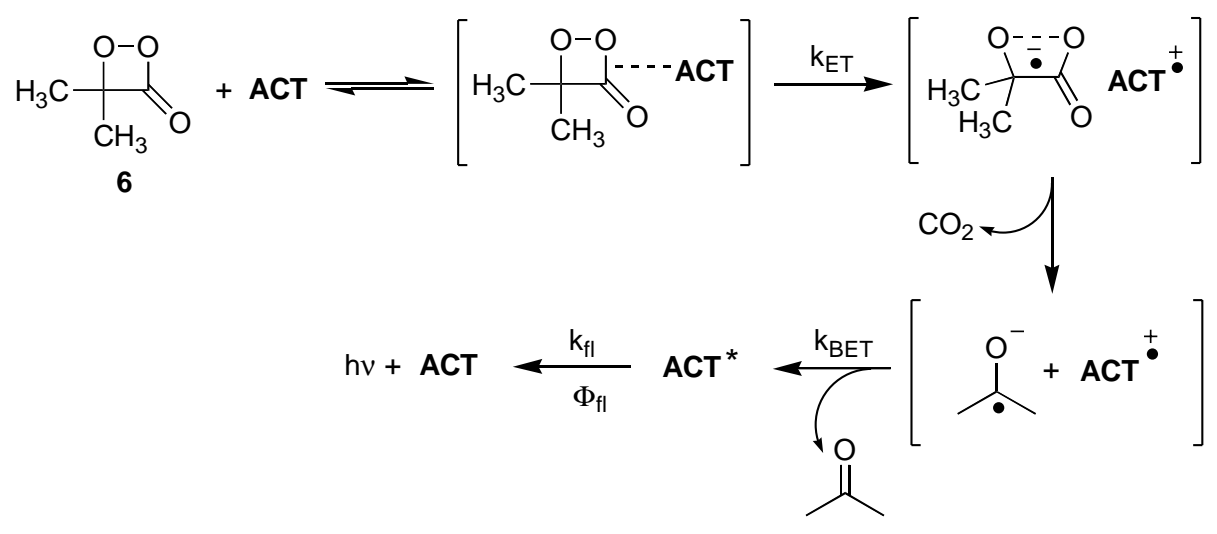


<smiles>COC1(c2cccc(O[R6](=O)[O-])c2)OOC12CC1CC3CC2CC(Cl)(C3)C1</smiles>

CSPD<smiles>CCCCCCC</smiles>

24<smiles>COc1cccc(CC2OOC2(C)C)c1</smiles>

25 do mecanismo CIEEL realizados com AMPPD e CSPD demonstraram que, apesar dos passos propostos para a decomposição catalisada envolverem íons $\mathrm{H}^{+}$e $\mathrm{OH}^{-}$, em $\mathrm{pH}$ alcalino e condições de estado estacionário, apenas o passo da desfosforilação mostra uma dependência acentuada com o pH. Apesar da cinética de decomposição do dioxetano desprotegido mudar com o $\mathrm{pH}$, os rendimentos de quimiluminescência são independentes, apresentando valores médios de $(7,5 \pm 0,3) 10^{-6} \mathrm{E}$ mol $^{-1}$ para AMPPD e $(5,7 \pm 0,3) 10^{-6} \mathrm{E} \mathrm{mol}^{-1}$ para $\mathbf{C S P D}^{60}$.

Em um trabalho recente ${ }^{61}$ descrevemos a síntese e as propriedades de quimiluminescência dos dioxetanos 24 e 25 com o objetivo de verificar a ocorrência de decomposição catalisada por transferência de elétron a partir do íon fenolato (gerado através da desproteção por íons fluoreto do grupo trialquilsilila), ora diretamente ligado ao anel peroxídico (24) ora distante deste através de um átomo de carbono (25). Enquanto tais compostos possuem alta estabilidade térmica $\left(\Delta \mathrm{G}^{\neq} \cong 25 \mathrm{kcal}\right.$ $\left.\mathrm{mol}^{-1}\right)$, levando à formação preferencial de espécies excitadas triplete em sua decomposição unimolecular, em presença de íons fluoreto, as velocidades de decomposição aumentam drasticamente, sendo formadas preferencialmente espécies excitadas singlete, com altos rendimentos de quimiluminescência: 1,00 e $0,010 \mathrm{E} \mathrm{mol}^{-1}$, respectivamente. A observação de catálise na decomposição de 25 constitui o primeiro exemplo de um mecanismo CIEEL intramolecular em 1,2-dioxetanos, iniciado pela transferência de elétron de um doador que não está diretamente ligado ou conjugado ao anel peroxídico ${ }^{62}$.

Os resultados obtidos podem ser explicados através de um esquema mecanístico (Esquema 10) análogo ao proposto para a decomposição catalisada da 3,3-dimetil-1,2-dioxetanona $(\mathbf{6})^{62,63}$.

Em um primeiro passo forma-se o fenolato, responsável pela transferência de elétron para o anel peroxídico, gerando um biradical ânion. Este último pode sofrer fragmentação segundo as rotas A e B, o que explicaria as diferenças observadas entre os rendimentos de quimiluminescência obtidos para 24 e 25. Segundo o Esquema 10 - rota $\mathrm{A}$, na decomposição de $\mathbf{2 4}$, devido ao substituinte aromático diretamente ligado ao anel, após a fragmentação seriam gerados formalmente um ânionradical de um composto carbonílico aromático e um fragmento neutro. Já no caso de $\mathbf{2 5}$, após a fragmentação seriam gerados o ânion-radical derivado do composto carbonílico não-conjugado e um fragmento neutro. Portanto, no caso de 24, o ânionradical gerado representaria o próprio estado excitado do produto, o fato de $\Phi^{\mathrm{S}}$ ser igual a 1,00 indica que a estrutura eletrônica de transferência de carga, realmente corresponde a um estado eletronicamente excitado do 3-fenoxibenzaldeído ${ }^{61-63}$. No caso de 25, o processo de retro-transferência seria dificultado, devido à impossibilidade de conjugação eletrônica entre as espécies doadora e receptora de elétron, reduzindo assim a eficiência quântica. Uma segunda possibilidade de explicação para os diferentes rendimentos singlete observados, seria a geração do ânion-radical derivado da acetona no caso de $\mathbf{2 5}$ (Esquema 10 - rota $\mathrm{B}$ ), pois não existe mais a estabilização do ânion-radical devido à conjugação com o substituinte aromático, sendo necessário um processo de retro-transferência de elétron intermolecular para gerar o fenolato excitado. Os rendimentos de quimiluminescência inferiores observados para $\mathbf{2 5}$ poderiam ser atribuídos ao escape da gaiola do solvente do par radicalar, cuja aniquilação é responsável pela formação de estados eletronicamente excitados.

Mais recentemente, foi relatada a dependência dos rendimentos quânticos de quimio-excitação em função da viscosidade do meio na decomposição catalisada por fluoreto de $\mathbf{1 6 b}^{64}$, o que levou os autores a concluir que a retrotransferência de elétron

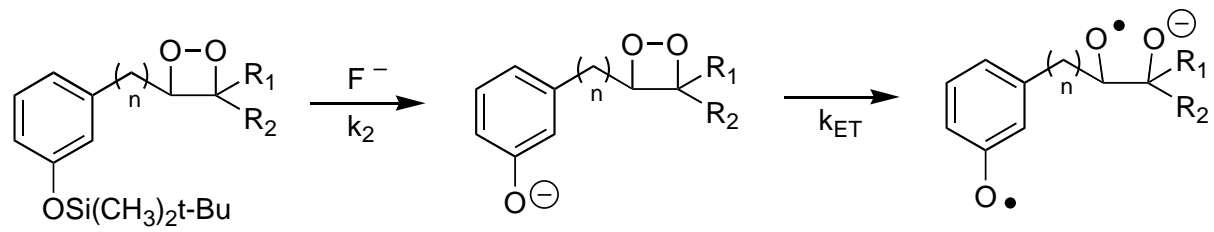

$24 \mathbf{n}=\mathbf{0} ; \mathrm{R}_{1}=\mathrm{CH}_{3} ; \mathrm{R}_{2}=\mathrm{C}_{2} \mathrm{H}_{5}$ $25 \mathrm{n}=1 ; \mathrm{R}_{1}=\mathrm{R}_{2}=\mathrm{CH}_{3}$

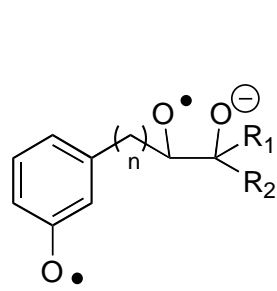<smiles>[R7]C([R7])=O</smiles><smiles>CCCCCC</smiles><smiles>CCC(=O)Nc1cccc(O)c1</smiles>

hv $560 \mathrm{~nm}$ 
deva ocorrer intermolecularmente. Segundo a proposta mecanística, após geração do fenolato ocorre a transferência de elétron e clivagem do anel peroxídico gerando o radical-ânion 26 e o radical 27 dentro da gaiola do solvente (Esquema 11). Esta proposta mecanística, a princípio, contradiz a discussão apresentada para explicar os altos rendimentos de quimiluminescência obtidos para 24, segundo a qual o processo de retrotransferência de elétron (BET - "back-electron transfer") ocorreria intramolecularmente e não intermolecularmente.
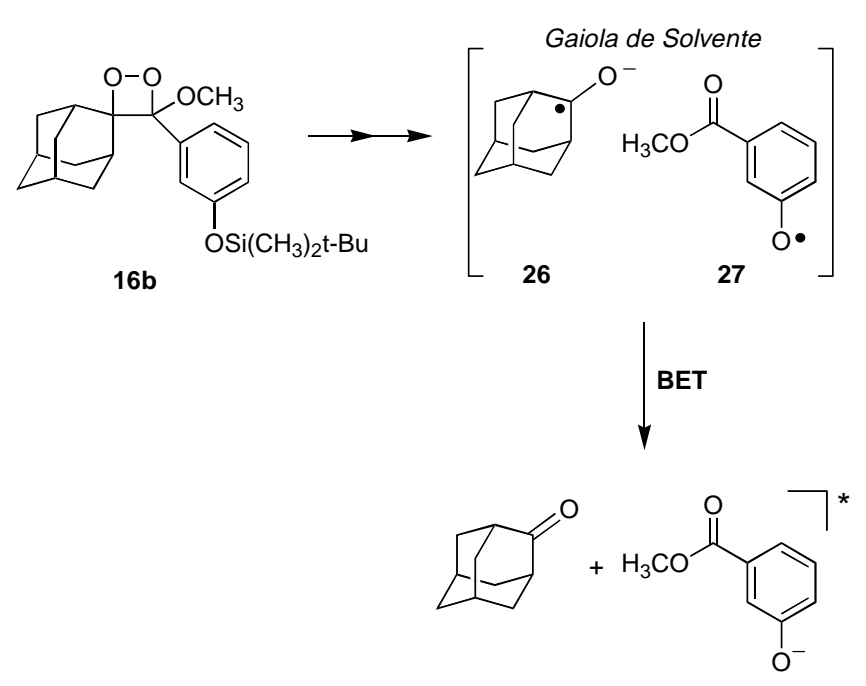

Esquema 11

Apesar das evidências experimentais apresentadas serem bastante convincentes com relação ao aumento dos rendimentos de quimiluminescência em função da viscosidade do meio, indicando a ocorrência de um passo intermolecular na seqüência CIEEL, as conclusões obtidas pelos autores parecem surpreendentes, levando-se em consideração o conhecimento atual sobre a clivagem de peróxidos catalisada por transferência de elétron em processos inter- e intramoleculares. Os rendimentos de quimiluminescência obtidos em sistemas CIEEL intermoleculares, como por exemplo os compostos $\mathbf{4 , 6}$ e 7, são geralmente muito baixos, com rendimentos quânticos singlete $\left(\Phi^{\mathrm{S}}\right)$ da ordem de $10^{-4} \mathrm{E} \mathrm{mol}^{-1}$ (Catálise Intermolecular) ${ }^{29,56}$. A única reação quimiluminescente que deve envolver um mecanismo CIEEL intermolecular com rendimentos de quimiluminescência comprovadamente altos é o sistema peróxi-oxalato ${ }^{65-67}$ sendo que ainda não foi comprovada inequivocamente a ocorrência da seqüência CIEEL como responsável pelo passo da excitação ${ }^{68,69}$. Um trabalho recente do nosso grupo de pesquisa mostra claramente que o passo da quimio-excitação desta reação envolve uma transferência de elétron, de acordo com o mecanismo CIEEL, porém, este estudo também demonstra a necessidade de mais evidências experimentais para comprovar a ocorrência do mecanismo CIEEL na reação quimiluminescente do peróxi-oxalato ${ }^{70}$.

Uma das razões consideradas responsáveis para os baixos $\Phi^{S}$ destes sistemas CIEEL intermoleculares é a possibilidade do escape do par de radicais íons da gaiola do solvente antes da ocorrência da retro-transferência de elétron $\left(\mathrm{k}_{\mathrm{BET}}\right.$, esquema 8). $\mathrm{O}$ escape da gaiola deve levar à formação de produtos no estado fundamental e por isso contribui para diminuir o rendimento de quimiluminescência. Por outro lado, vários 1,2-dioxetanos com substituintes apropriados mostram decomposição induzida com rendimentos de quimiluminescência muito altos, entre eles o próprio composto $\mathbf{1 6 b}$, utilizado nos estudos da viscosidade, o qual possui um $\Phi^{\mathrm{S}}$ de cerca de $0,25 \mathrm{E} \mathrm{mol}^{-1}$. Além desse derivado pode ser destacado o 1,2-dioxetano $\mathbf{2 4}$, cuja decomposição induzida ocorre com um rendimento $\Phi^{\mathrm{S}}=1,0 \mathrm{E} \mathrm{mol}^{-1}$, ou seja, cada molécula de reagente leva a geração de um estado excitado singlete do produto ${ }^{62}$. Baseado nesses fatos, a rota A do esquema 10 parece a proposta mecanística mais adequada, pois não há a necessidade de uma transferência intermolecular de elétrons e o estado excitado do produto é formado diretamente pela clivagem da ligação C-C (vide acima).

Estudos da decomposição catalisada por fluoreto do 3,3diisopropil-4-metóxi-4-(silóxi-2-naftil)-1,2-dioxetanos (28) revelaram que o padrão de substituição par/ímpar do substituinte aromático afeta os rendimentos de quimiluminescência ${ }^{71}$. Os compostos meta-substituídos (28b, 28c, 28e - padrão de substituição ímpar) exibem altos rendimentos de quimiluminescência enquanto os para-substítuidos (28a, 28d, 28f) apresentam uma emissão de luz muito fraca.

Resultados semelhantes são obtidos quando comparados os rendimentos de quimiluminescência de $\mathbf{2 4}$ e 29. Enquanto a decomposição de $\mathbf{2 4}$ emite uma luz amarela intensa durante alguns segundos, no segundo caso observa-se uma emissão muito fraca com um tempo de vida extremamente curto $^{72}$.

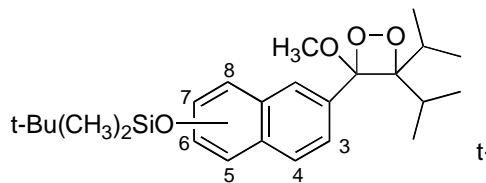

28a isômero 3; b isômero 4; c isômero 5 ; $\mathbf{d}$ isômero 6 ; e isômero 7; f isômero 8.

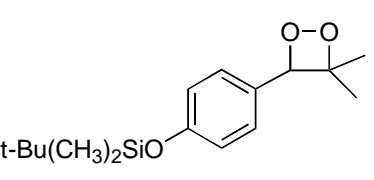

29

\section{CONCLUSÕES}

Em todos os exemplos aqui descritos, não há dúvida de que uma transferência de elétron ou de carga deva desempenhar um papel importante no processo de quimiluminescência, além disso, as reações com altos rendimentos de quimiluminescência são claramente excelentes modelos para o estudo de processos bioluminescentes e fortes candidatos para aplicações analíticas. Contudo, como tais reações são intramoleculares e muito rápidas, os passos reacionais são mais difíceis de serem estudados, o que leva alguns cientistas a questionar severamente o mecanismo postulado ${ }^{26,73}$.

É importante ressaltar que, muitas reações simples em fase gasosa, até hoje, não tiveram seu mecanismo totalmente esclarecido, portanto, não é surpreendente que um processo tão complexo como o proposto por Schuster, envolvendo duas transferências sucessivas de elétrons, clivagens de ligações e mudanças na superfície de potencial eletrônico, ainda desperte dúvidas. Este é o principal motivo pelo interesse mecanístico de alguns grupos de pesquisa pelo processo. A elucidação dos passos fundamentais para a geração de luz: a transferência (ET) e retrotransferência (BET) de elétron, assim como dos intermediários propostos no processo, devem fornecer ferramentas importantes para que muito em breve novos compostos peroxídicos com características cada vez mais favoráveis para aplicações analíticas possam ser obtidos e posteriormente comercializados.

\section{AGRADECIMENTOS}

À FAPESP, FINEP-PADCT e ao CNPq pelo apoio financeiro e ao M.Sc. Erick L. Bastos pela ajuda na confecção das ilustrações e revisão do manuscrito.

\section{REFERÊNCIAS}

1. Campbell, A. K.; Chemiluminescence: Principles and Applications in Biology and Medicine; Ellis Horwood Ltd., Chichester (England), 1988.

2. Adam, W.; Pure Appl. Chem. 1980, 52, 2591.

3. Schuster, G. B.; Schmidt, S. P.; Adv. Phys. Org. Chem. 1982, $18,187$. 
4. Faulkner, L. R.; Int. Rev. Sci.: Phys. Chem. Ser. Two 1976, 9, 213.

5. Koo, J. -Y.; Schuster, G. B.; J. Am. Chem. Soc. 1978, $100,4496$.

6. Schuster, G. B.; Dixon, B.; Koo, J.-Y; Schmidt, S.P.; Schmidt, J. P.; Photochem. Photobiol. 1979, 30, 17.

7. Montano, L. A.; Ingle, J. D. Jr.; Anal. Chem. 1979, 51, 926.

8. Mendenhall, G. B.; Angew. Chem. Int. Ed. Engl. 1977, $16,225$.

9. Williams, D. C. III; Seite, W. R.; Anal. Chem. 1976, $48,1478$.

10. Wilson, T.; Int. Rev. Sci.: Phys. Chem. Ser. Two 1976, 9, 265 .

11. a. Staudinger, H.; Chem. Ber. 1925, 58, 1075; b. Staudinger, H.; Dyckerhoff, K.; Klever, H. W.; Ruzicka, L.; Chem. Ber. 1925, 58, 1079.

12. a. Kopecky, K. R.; Mumford, C.; Can. J. Chem. 1969, 47, 709; b. Kopecky, K. R.; Mumford, C.; Abstracts, 51 $\underline{s t}$ Annual Conference of Chemical Institute of Canada, Vancouver (B C), 1968, p. 41.

13. Bechara, E. J. H.; Wilson, T.; J. Org. Chem. 1980, 45, 5261.

14. Adam, W.; Cilento, G.; Chemical and Biological Generation of Excited States; Academic Press, New York, 1982.

15. Wilson, T.; Halpern, A. M.; J. Phys. Org. Chem. 1995, 8, 359.

16. McCapra, F.; Chem. Comm. 1968, 155.

17. Turro, N. J.; Devaquet, A.; J. Am. Chem. Soc. 1975, 97, 3858.

18. Adam, W.; Baader, W. J.; J. Am. Chem. Soc. 1985, 107, 410.

19. O'Neal, H. E.; Richardson, W. H.; J. Am. Chem. Soc. 1970, 92, 6553 .

20. a. Zimmerman, H. E.; Keck, G. E.; Pflederer, J. L.; J. Am. Chem. Soc. 1976, 98, 5574; b. Zimmerman, H. E.; Keck, G. E.; J. Am. Chem. Soc. 1975, 97, 3527.

21. Richardson, W. H.; Batinica, G.; Janota-Perret, K.; Miller, T.; Shen, D.; J. Org. Chem. 1991, 56, 6140.

22. Richardson, W. H.; Lovett, M. B.; Olson, L.; J. Am. Chem. Soc. 1989, 54, 3523.

23. a. Adam, W.; Heil, M.; J. Am. Chem. Soc. 1992, 114, 8807, b. Adam, W.; Andler, S.; J. Am. Chem. Soc. 1994, 116,5674 .

24. a. Lima, D. F.; Dissertação de Mestrado; Instituto de Química, Universidade de São Paulo, S. Paulo, 1996; b. Murphy, S.; Adam, W.; J. Am. Chem. Soc. 1996, 118, 12916.

25. Adam, W.; Cilento, G.; Angew. Chem. Int. Ed. Engl. 1983, 22, 529.

26. Wilson, T.; Photochem. Photobiol. 1995, 62, 601.

27. Schuster, G. B.; Acc. Chem. Res. 1979, 12, 366.

28. Schmidt, S. P.; Schuster, G. B.; J. Am. Chem. Soc. 1980, 102, 306.

29. Catalani, L. H.; Wilson, T.; J. Am. Chem. Soc. 1989, $111,2633$.

30. White, E. H.; Wörther, H.; Seliger, H. H.; McElroy, W. D.; J. Am. Chem. Soc. 1966, 88, 2015.

31. McCapra, F.; Beheshti, I.; Burford, A.; Hann, R. A.; Zaklika, K. A.; J. Chem. Soc., Chem. Comm. 1977, 944.

32. McCapra, F.; J. Chem. Soc., Chem. Comm. 1977, 946.

33. McCapra, F.; Progress in Organic Chemistry; eds. Carruthers, W.; Sutherland, J. K., 1973, vol 8, p. 254.

34. Lee, S.; Singer, L. A.; J. Am. Chem. Soc. 1980, 102, 3823.

35. Nakamura, K.; Goto, T.; Photochem. Photobiol. 1979, 30, 27.

36. Zakika, K .A.; Kissel, T.; Thayer, A. L.; Burns, P. A.; Schaap, A. P.; Photochem. Photobiol. 1979, 30, 35.

37. Schaap, A. P. \& Gagnon, S. D.; J. Am. Chem. Soc. 1982, 104, 3504.

38. Schaap, A. P.; Chen, T-S.; Handley, R. S.; De Silva, R.; Giri, B. P.; Tetrahedron Lett. 1987, 28, 1155.

39. Schaap, A. P.; Handley, R. S.; Giri, B. P.; Tetrahedron Lett. 1987, 28, 935.

40. Schaap, A. P.; Sandison, M. D.; Handley, R. S.; Tetrahedron Lett. 1987, 28, 1159.
41. Adam, W.; Schulz, M. H.; Chem. Ber. 1992, 125, 2455.

42. Adam, W.; Fell, R.; Schulz, M. H.; Tetrahedron 1993, 49, 2227.

43. Adam, W.; Reinhardt, D.; J. Chem. Soc., Perkin Trans. 2, 1994, 1503 .

44. Matsumoto, M.; Ishihara, T.; Watanabe, N.; Hiroshima, T.; Tetrahedron Lett. 1999, 40, 457.

45. Watanabe, N.; Suganuma, H.; Kobayashi, H.; Mutoh, H.; Katao, Y.; Matsumoto, M.; Tetrahedron 1999, 55, 4287.

46. Dodeigne, C.; Thunus, L.; Lejeune, R.; Talanta 2000 , 51,415 .

47. Southern, E. M.; J. Mol. Biol. 1975, 98, 503.

48. Bronstein, I.; Voyta, J. C.; Lazzari, K. G.; Murphy, O.; Edwards, B.; Kricka, L. J.; Biotechniques 1990, 8, 310.

49. Bronstein, I.; Edwards, B.; Voyta, J. C.; J. Biolum. Chemilum. 1989, 4, 99

50. Bronstein, I.; Voyta, J. C.; Clin. Anal. 1989, 35, 1856.

51. Bronstein, I.; Voyta, J. C.; Edwards, B.; Anal. Biochem. 1989, $180,95$.

52. Schaap, A. P.; Akhavan, H.; Romano, L. J.; Clin. Chem. 1989, 35, 1893.

53. Bronstein, I.; Voyta, J. C.; Vant Erve, Y.; Kricka, L.J.; Clin. Chem. 1991, 37, 1526.

54. Thorpe, G. H. G.; Bronstein, I.; Kricka, L.J., Edwards, B.; Voyta, J. C.; Clin. Chem. 1989, 35, 2319.

55. Beale, E. G.; Deeb, E. A.; Handley, R. S.; Akhavan-Tatti, H.; Schaap, A. P.; Biotechniques 1992, 12, 320.

56. Wilson, T.; Singlet Oxygen; A. Frimer ed., CRC Press, Baton Rouge, L. A. 1985, vol II, p.37.

57. Adam, W.; Reinhardt, D.; Sahamoller, C. R.; Analyst 1996, $121,1527$.

58. Trofimov, A. V.; Mielke, K.; Vasil'ev, R. F.; Adam, W.; Photochem. Photobiol. 1996, 63, 463.

59. Martin, C.; Bresnick, L.; Juo, R. R.; Voyta, J. C.; Bronstein, I.; Biotechniques 1991, 11, 110

60. Adam, W; Bronstein, I.; Edwards, B.; Engel, T.; Reinhardt, D.; Schneider, F. W.; Trofimov, A. V.; Vasil'ev, R. F.; J. Am. Chem. Soc. 1996, 118, 10400.

61. Nery, A.L.P.; Röpke, S.; Catalani, L. H.; Baader, W.J.; Tetrahedron Lett. 1999, 40, 2443.

62. a. Nery, A.L.P.; Weiss, D.; Catalani, L. H.; Baader, W.J.; Tetrahedron 2000, 56, 5317. b. Nery, A. L. P.; Tese de Doutoramento, Instituto de Química, Universidade de São Paulo, S. Paulo, 1997.

63. Nery, A.L.P.; Catalani, L. H.; Röpke, S.; Nunes, G. I. P.; Baader, W. J.; Bioluminescence and Chemiluminescence: Perspectives for the 21st Century, eds.: A. Roda, M. Pazzagali, L. J. Kricka; P. E. Stanley; John Wiley \& Sons, Chichester 1999, p. 45.

64. Adam, W.; Bronstein, I.; Trofimov, A. V.; Vasil’ev, R. F.; J. Am Chem. Soc. 1999, 121, 958.

65. Rauhut, M. M.; Acc. Chem. Res. 1969, $2,80$.

66. Catheral, C. L. R.; Palmer, T. F.; Cundall, R. B.; J. Biolum. Chemilum. 1989, 3, 147.

67. Stevani, C. V.; Lima, D. F.; Toscano, V. G.; Baader, W. J.; J. Chem. Soc., Perkin Trans. 2 1996, 989.

68. Stevani, C. V.; da Silva, S. M.; Baader, W. J.; Bioluminescence and Chemiluminescence: Perspectives for the 21st Century, eds.: A. Roda, M. Pazzagali, L. J. Kricka; P. E. Stanley; John Wiley \& Sons, Chichester 1999, p. 53.

69. Stevani, C. V.; Baader, W. J.; Quim. Nova 1999, 22, 715.

70. Stevani, C. V.; Silva, S. M.; Baader, W. J.; Eur. J. Org. Chem. 2000, 3961

71. Watanabe, N.; Kobayashi, H.; Azami, M. Matsumoto, M.; Tetrahedron 1999, 55, 6831.

72. Röpke, S.; Dissertação de Mestrado; Instituto de Química, Universidade de São Paulo, S. Paulo, 2000.

73. McCapra, F.; Bioluminescence and Chemiluminescence: Molecular Reporting from Photons; eds. J. W. Hastings, L. J. Kricka; P. E. Stanley; John Wiley \& Sons, Mass., 1997, p. 7. 